\title{
EVALUATION OF PAINFUL SHOULDER IN BASEBALL PLAYERS
}

Alberto Naoki Miyazaki', Marcelo Fregoneze², Pedro Doneux Santos ${ }^{3}$, Luciana Andrade da Silva ${ }^{3}$, Guilherme do Val Sella ${ }^{3}$, Adriano Fernando Mendes Junior ${ }^{4}$, André Lopes Soares ${ }^{4}$, Leandro Jun Aihara ${ }^{5}$, Sérgio Luiz Checchia ${ }^{6}$

\section{ABSTRACT}

Objective: To assess the relationship between shoulder mobility and strength and the presence of pain among baseball players. Methods: Between April and July 2009, 55 baseball players were assessed by the Shoulder and Elbow Group of the School of Medical Sciences, Santa Casa de Misericórdia, São Paulo. They were all males, aged between 15 and 33 years (mean of 21); they attended an average of three training sessions per week and had been doing this sport for a mean of 10 years. Results: 14 of the 55 players evaluated were pitchers, and 20 reported pain during the pitching motion. The mean values for lateral and medial rotation and range of motion (ROM) in the dominant shoulder were, respectively, $110^{\circ}, 61^{\circ}$ and $171^{\circ}$, with a statistically significant difference in relation to the non-dominant limb. Pitchers had greater gains in lateral rotation and deficits in medial rotation than did non- pitchers. Pain presented a statistically significant correlation with diminished ROM, greater length of time playing the sport and situations of "shoulder at risk". Conclusions: Statistically significant differences in dominant shoulder mobility were found, with increased lateral rotation, diminished medial rotation and smaller ROM, in relation to the contralateral limb. There was a statistically significant relationship between the pitcher's position and greater gain in lateral rotation and diminished medial rotation. There were statistically significant correlations between pain and diminished ROM, greater length of time playing the sport and situations of "shoulder at risk". There was a statistical tendency suggesting that players with diminished medial rotation of the dominant shoulder presented a relationship with pain.

Keywords - Baseball; Shoulder; Joint Range of Motion

\section{INTRODUCTION}

Injuries are common among athletes who practice throwing sports ${ }^{(1)}$ and, of these, injuries of the upper limbs represent around $75 \%$, the shoulder being the most commonly affected region ${ }^{(2)}$. The great demands placed on the shoulder and repeated movements cause adaptations to occur in the soft tissues and bones of these athletes: hypertrophy and shortening of the posterior capsule, lengthening of the anterior capsule, and increase in retroversion of the head of the humerus $^{(3)}$. Bach and Goldberg ${ }^{(4)}$ and Morgan ${ }^{(5)}$ suggest that insufficient contraction of the musculature of the posterior region of the shoulder (posterior portion of the deltoid muscle, supra- and infraspinal muscles, teres minor, trapezius, and biceps muscle of the arm)

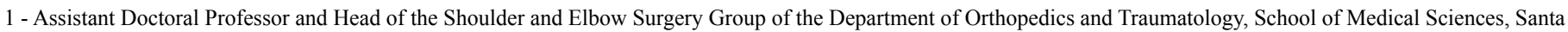
Casa de São Paulo - São Paulo, Brazil.

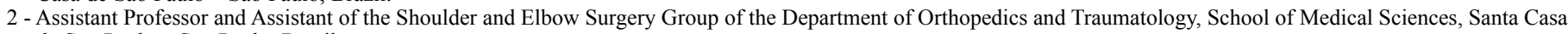
de São Paulo - São Paulo, Brazil.

3 - Assistant of the Shoulder and Elbow Surgery Group of the Department of Orthopedics and Traumatology, School of Medical Sciences, Santa Casa de São Paulo São Paulo, Brazil.

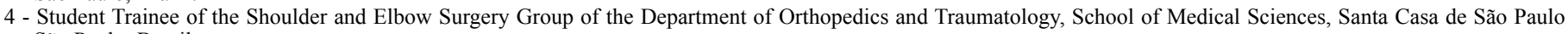
São Paulo, Brazil.

5 - Student of the School of Medical Sciences, Santa Casa de São Paulo.

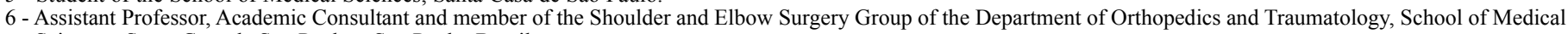
Sciences, Santa Casa de São Paulo - São Paulo, Brazil.

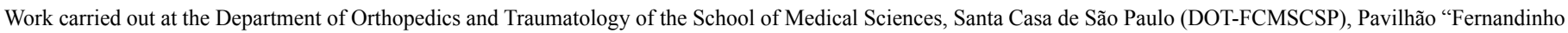
Simonsen". Director: Prof. Dr. Osmar Avanzi - São Paulo (SP), Brazil.

Correspondence: R. Dr. Cesário Mota Jr, 112 - Vila Buarque - 01221-020 - São Paulo - SP. Tel.: (11) 3222-6866. E-mail: ombro@ombro.med.br

Work received for publication: February 17, 2010; accepted for publication: April 6, 2010. 
in the deceleration phase of the pitching motion leads to cyclic stress in the joint capsule, particularly in the posterior inferior region, causing it to contract, resulting in glenohumeral internal rotation deficit (GIRD). Another hypothesis for the origin of posterior capsular contracture is scarring in response to repetition microtraumas caused by the throwing ${ }^{(6)}$. According to Braun et $\mathrm{al}^{(7)}$, GIRD originates from contracture of both the posterior capsule and the posterior band of the lower glenohumeral ligament. However, the etiology of the contracture has not been fully clarified ${ }^{(8)}$.

The kinematic of the shoulder joint is altered by retraction of the posterior inferior capsule, shifting the center of rotation of the head of the humerus to the posterosuperior region $^{(9)}$. This change, in turn, leads to abnormal contact between the joint surface of the rotator cuff and the posterior superior portion of the glenoid rim, causing pain and favoring their respective lesions ${ }^{(7,10)}$. Repeated throwing associated with the abovementioned alteration leads to a relative increase in length of the anterior inferior portion of the joint capsule, leading to a gain in lateral rotation (GLR) ${ }^{(7)}$. Another hypothesis for the gain in lateral rotation in these athletes is the increase in humeral retroversion, which can occur in the shoulders of athletes whose skeletal structures are still developing ${ }^{(3)}$.

Due to the abovementioned adaptations, the dominant shoulder movement in pitchers is altered, with an increase in lateral rotation and a decrease in internal rotation with the shoulder abducted $90^{\circ}(7)$ (Figure 1). This is a physiological adaptation to repeated throwing, which remains efficient and painless ${ }^{(7)}$ provided the balance between gain in lateral rotation and loss of internal rotation is maintained ${ }^{(11)}$. However, if there is an imbalance between the adaptations, the shoulder becomes susceptible to the onset of pain and development of injuries, leading to an entity termed by Burkhart et al "shoulder at risk"(11).

In addition to the changes in mobility, there are alterations in muscle trophism: in the dominant limb, according to Braun, there is a decrease in lateral rotation strength and an increase in strength of the internal rotators and adductors ${ }^{(7)}$. According to Magnusson et $\mathrm{al}^{(12)}$, there is a decrease in muscle strength in the dominant shoulder in professional baseball pitchers, compared with the non-dominant limb.

The objective of this work is to evaluate, in baseball players aged 15 years or over, the relationship between the values of mobility and shoulder strength, and the presence of pain.

\section{CASE STUDIES AND METHODS}

In the period of April to July 2009, 55 amateur baseball players were evaluated by the Shoulder and Elbow Group of the School of Medical Sciences, Santa Casa de São Paulo - Pavilhão "Fernandinho Simonsen". The criteria for inclusion were: age 15 years or over, minimum frequency of two training sessions per week, no breaks of more than a month in the last six months, and absence of any type of diagnosed shoulder injury. The criteria for exclusion were: age under 15 years, frequency less than two training sessions per week, break in training of more than one month in the last six months, and presence of diagnosed shoulder injury. All the players were male, with an average age of 21 years (age range of 15 to 33 years), 49 (89\%) of the athletes

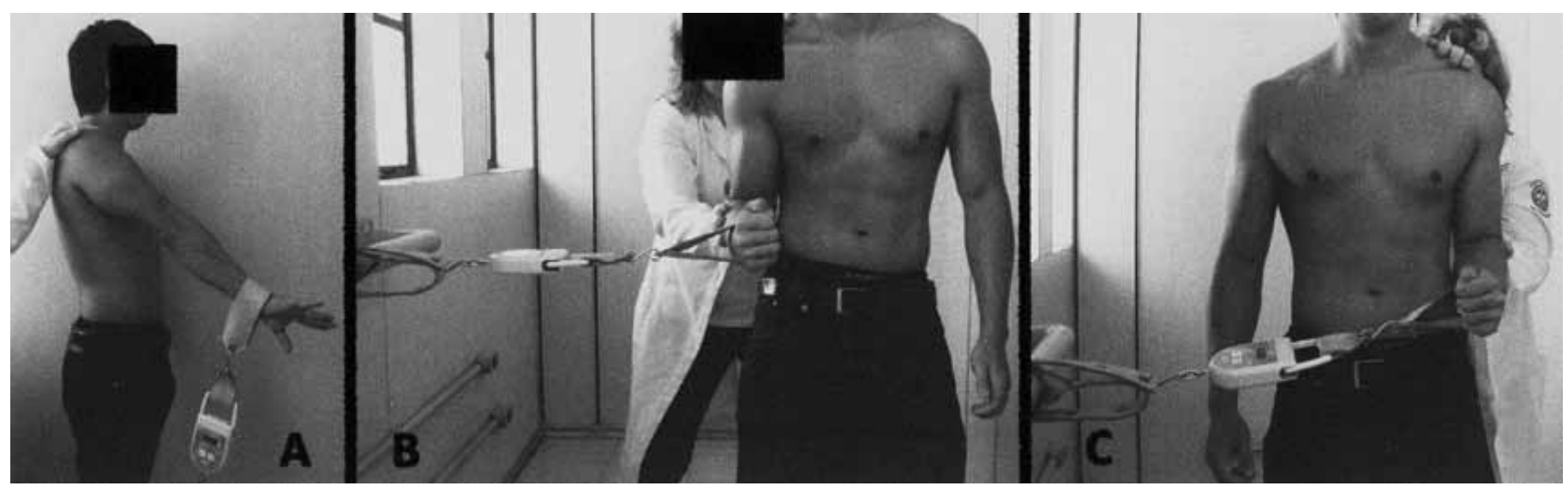

Figure 1 - Photographs of the athlete's shoulders in $90^{\circ}$ abduction: A) lateral rotation of the dominant shoulder; B) lateral rotation of the non-dominant shoulder; C) medial rotation of the dominant shoulder; D) medial rotation of the non-dominant rotation. 
were right-handed and six (11\%) were left-handed. The average length of time they had played the sport was 10 years (two had played for 25 years), and they had an average of three training sessions per week. Of the 55 athletes evaluated, $14(25 \%)$ were pitchers and 41 (75\%) played in other positions.

With prior consent, the players were evaluated according to a protocol (Annex 1) which included data on the time spent playing the sport, the athlete's position on the playing field, history of pain during pitching motion, joint movement, and muscle strength.

Joint mobility was evaluated according to the recommendations of the society of American Shoulder and Elbow Surgeons (ASES) ${ }^{(13)}$ and based on the parameters described by Donatelli et $\mathrm{al}^{(14)}$ for lateral rotation (LR90) and medial rotation (MR90) of the shoulder, with the player in the supine position, the shoulder abducted $90^{\circ}$, the elbow flexed $90^{\circ}$ and the forearm in neutral rotation (Figure 1). All the measurements were performed with a graduated goniometer $\left(\mathrm{Carci}^{\circledR}\right)$ and the non-dominant shoulder was used as a parameter to calculate possible gains or losses in range of motion.

The range of motion (ROM) was calculated by totaling the values of lateral and medial rotation of the shoulder in abduction of $90^{\circ}$. The GLR was measured by the difference between the values for lateral rotation in abduction of $90^{\circ}$ of the dominant and non-dominant

Annex 1 - Baseball players evaluation protocol.

\begin{tabular}{|c|c|c|c|c|}
\hline \multicolumn{5}{|c|}{ Baseball players evaluation protocol } \\
\hline \multicolumn{2}{|l|}{ Name } & \multicolumn{3}{|c|}{ Age } \\
\hline Club & Position & \multicolumn{3}{|c|}{ Right/Left handed } \\
\hline \multicolumn{5}{|l|}{ Tel: } \\
\hline \multicolumn{2}{|c|}{ Time spent playing } & \multicolumn{3}{|c|}{ Frequency of training sessions } \\
\hline \multicolumn{5}{|c|}{ Pain Time interval } \\
\hline \multicolumn{2}{|c|}{ ( ) Rest } & ( ) Continuous & & \\
\hline \multicolumn{2}{|c|}{ While pitching: ( ) Cocking } & ( ) Acceleratio & $n($ & All \\
\hline \multirow[t]{5}{*}{ Mobility } & \multicolumn{2}{|c|}{ Elevation (scapular plane) } & RS & LS \\
\hline & \multicolumn{2}{|c|}{ Lateral rotation $0^{\circ}(\mathrm{LR} 0)$} & $\mathrm{RS}$ & LS \\
\hline & \multicolumn{2}{|c|}{ Lateral rotation $90^{\circ}(\mathrm{LR} 90)$} & $\mathrm{RS}$ & LS \\
\hline & \multicolumn{2}{|c|}{ Medial rotation $0^{\circ}$ (vertebral level) (MR0) } & RS & LS \\
\hline & \multicolumn{2}{|c|}{ Medial rotation $90^{\circ}(\mathrm{LR} 90)$} & RS & LS \\
\hline \multirow[t]{5}{*}{ Força } & \multicolumn{2}{|c|}{ Elevation (scapular plane) } & RS & LS \\
\hline & \multicolumn{2}{|c|}{ Lateral rotation $0^{\circ}(\mathrm{LR} 0)$} & RS & LS \\
\hline & \multicolumn{2}{|c|}{ Lateral rotation $90^{\circ}$ (LR90) } & RS & LS \\
\hline & \multicolumn{2}{|c|}{ Medial rotation $0^{\circ}(\mathrm{MR} 0)$} & RS & LS \\
\hline & \multicolumn{2}{|c|}{ Medial rotation $90^{\circ}(\mathrm{LR} 90)$} & $\mathrm{RS}$ & LS \\
\hline
\end{tabular}

shoulders. The GIRD was calculated by the difference between the medical rotation of the shoulder at $90^{\circ}$ of abduction of the dominant and non-dominant shoulders. The ratio between the GIRD and the GLR was calculated to determine which athletes have "shoulder at risk", as described by Burkhart et al ${ }^{(11)}$.

The isometric contraction strength was measured using a manual dynamometer (KERN $\left.{ }^{\circledR} \mathrm{CH} 50 \mathrm{~K} 50\right)$ calibrated according to the manufacturer's specifications. The measurements were checked in the same planes of movements, according to the recommendations of the $\operatorname{ASES}^{(13)}$ and Donatelli et al ${ }^{(14)}$ (Figure 2). To prevent compensatory muscle action in the measurements, a vertical resistance force was applied to the limb being evaluated, and the joint was kept at the appropriate angle. In each of the axes evaluated, three measurements of maximum strength measurements were taken, and the maximum values for strength (in kilograms force) were noted for each. The average for the three repetitions was determined for each axis. The contralateral shoulder was evaluated in the same way.

The data were evaluated statistically using the program SPSS (Statistical Package for Social Sciences), version 13.0, adopting a level of significance of 5\% $(p<0.050)$. The presence of the variable pain was compared with the data on the player's position in the field, frequency of training and situation of "shoulder at risk", applying the Chi-square test. The comparison of pain and time spent playing the sport was calculated by the Student's t-test.

The values of the variables mobility and strength

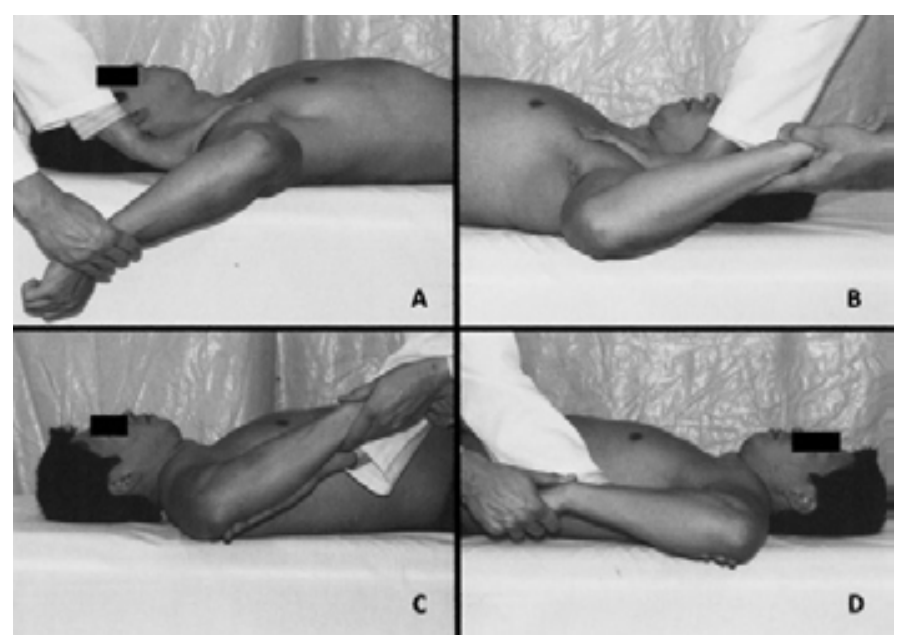

Figure 2 - Photographs of the muscle strength measurements in the following planes: A) elevation; B) medial rotation in zero degrees abduction; $C$ ) lateral rotation in zero degrees abduction. 
in the LR90 and MR90 axes, as well as ROM, both for the dominant limb, were compared with the values for the non-dominant limb for these same parameters, through the Wilcoxon signed-rank test.

Fisher's exact test was used to determine the relations between the variable pain and the variables mobility LR90 and MR90, strength LR90 and MR90, ROM, GIRD and GLR, as well as in the calculation of relationships between playing position and ROM, GIRD and GLR.

To calculate the statistical correlation between the variables pain and mobility and MR90, the athletes' averages were divided into two groups. In the first group, the averages of the dominant limb were lower than those of the non-dominant limb. In the second group, the average values were equal or greater than the dominant limb compared to the non-dominant limb.

The variables mobility in the planes of movement in LR90, strength in MR90 and LR90 were submitted to verification of the statistical correlation with the variable pain, with distinct formation of the groups. For LR90, the first group was comprised of higher average values of the dominant limb than the nondominant limb, and the second group consisted of equal or lower values. For strength in MR90, the values expected to comprise group 1 would be higher averages for the dominant limb than for the non-dominant limb, and in group 2, equal or lower values. And for strength in the LR90 plane, the first group was comprised of the values for the dominant limb that were lower than the values for the nondominant limb, while the second group consisted of equal or higher values. The average values for ROM were also correlated with the variable pain. The group of expected values was formed by the values for the dominant limb, which are lower than those of the nondominant limb, while the second group had values for ROM that were equal or higher for the dominant than for the non-dominant limb.

\section{RESULTS}

The statistical correlation between the player's position and the history of pain was not significant $(\mathrm{p}=$ $1.655)$. Of the 55 athletes evaluated, 20 (36\%) reported pain at some time when pitching, with an average period of pain of 31 months (three to 120 months). These 20 athletes $(36 \%)$ with a history of pain had played the sport for an average time of 133 months (24 to 276 months) while the 35 (64\%) asymptomatic athletes had played the sport for 96 months on average (three to 300 months). The statistical correlation was observed between length of time playing the sport and pain $(\mathrm{p}=$ 0.016). The weekly frequency of training ranged from two to four training sessions per week. The statistical correlation was calculated between this variable and pain, and was not statistically significant $(\mathrm{p}=0.286)$.

The average measurements for movements and strength in the planes of elevation, lateral rotation and medial rotation in abduction of zero degrees, for the dominant and non-dominant limbs, are shown in Table 1.

Table 1 - Results of the measurement of mobility and strength.

\begin{tabular}{c|c|c}
\hline Axis & Mobility (degrees) & Strength (kgf) \\
\hline ELE DOM & 156 & 9.59 \\
\hline ELE NDOM & 158 & 9.41 \\
\hline LRO DOM & 78 & 9.85 \\
\hline LRO NDOM & 76 & 9.58 \\
\hline MRO DOM & T8 & 13.51 \\
\hline MRO NDOM & T6 & 13.37
\end{tabular}

Legend - ELE: elevation, LR 0: lateral rotation at zero degrees of abduction, MR 0 : medial rotation at zero degrees of abduction, DOM: dominant limb, NDOM: nondominant limb, T: thoracic vertebra.

Source: Outpatient clinic of the Shoulder and Elbow Group of the DOT-ISCMSP

In the plane of lateral rotation in abduction of 90 degrees (LR90), the values for the variables mobility and strength of the dominant and non-dominant limbs are described in Table 2. The averages for mobility of the dominant and non-dominant limbs were compared, with a value of significance of $p=0.003$, demonstrating a statistically significant difference between the groups. The same test was performed for the variable strength, comparing the averages for the dominant and non-dominant limbs in the plane of lateral rotation in abduction of 90 degrees (LR90), with $p=0.325$, demonstrating no statistically significant difference between the groups evaluated.

Table 2 - Results of mobility and strength for lateral rotation at 90 degrees of abduction.

\begin{tabular}{c|c|l|c|l}
\hline & $\begin{array}{c}\text { Mobility } \\
\text { (degrees) }\end{array}$ & & $\begin{array}{c}\text { Strength } \\
\text { (kgf) }\end{array}$ & \\
\hline LR90 DOM & 110 & & 13.67 & \\
\hline LR90 NDOM & 105 & $\mathrm{p}=0.003$ & 13.52 & $\mathrm{p}=0.325$ \\
\hline
\end{tabular}

Legend - LR90: lateral rotation at 90 degrees of abduction, DOM: dominant limb, NDOM: non-dominant limb.

Source: Outpatient clinic of the Shoulder and Elbow Group of the DOT-ISCMSP 
Table 3 shows the results of the averages for mobility and strength measured in the plane of medial rotation with 90 degrees of abduction of the shoulder (MR90). The values for mobility of the dominant and non-dominant limbs in this plane of movement were compared, with a value of $\mathrm{p}<0.001$, which is statistically significant. In the statistical analysis of the values for strength, we found $p=0.186$, which is not statistically significant.

Table 3 - Results of mobility and strength for medial rotation at 90 degrees of abduction.

\begin{tabular}{l|c|l|c|c}
\hline & $\begin{array}{c}\text { Mobility } \\
\text { (degrees) }\end{array}$ & & $\begin{array}{c}\text { Strength } \\
\text { (kgf) }\end{array}$ & \\
\hline MR90 DOM & 61 & & 11.97 & \\
\hline MR90 NDOM & 75 & $\mathrm{p}<0.001$ & 12.25 & $\mathrm{p}=0.186$ \\
\hline
\end{tabular}

The averages for range of motion (ROM) of the dominant and non-dominant limbs are described in Table 4. The statistical correlation between these values was calculated, obtaining a value of $p<0.001$, demonstrating a statistically significant difference between the groups. The average values for GLR and GIRD are shown in the same table.

Table 4 - Results of range of motion, gain in lateral rotation and glenohumeral internal rotation deficit in the shoulder.

\begin{tabular}{c|c|c}
\hline & Mobility (degrees) & \\
\hline ROM DOM & 171 & $\mathrm{p}<0.001$ \\
\hline ROM NDOM & 181 & \\
\hline GLR & 4.56 & \\
\hline GIRD & 15.53 & \\
\hline
\end{tabular}

Legend - ROM: range of motion, GLR: gain in lateral rotation, GIRD: glenohumeral internal rotation deficit in the shoulder, DOM: dominant limb, NDOM: non-dominant limb. Source: Outpatient clinic of the Shoulder and Elbow Group of the DOT-ISCMSP

The average values were calculated for GLR and GIRD of the pitchers and non-pitchers. For the first, averages of $10.36^{\circ}$ and $21.07^{\circ}$ were obtained, respectively; for the non-pitchers, averages of $2.5^{\circ}$ and $13.57^{\circ}$ were obtained, respectively. The relations between GLR and playing position, and between GIRD and playing position were calculated with $\mathrm{p}=0.013$ and $p=0.033$, respectively, which means the pitchers suffered greater gains in lateral rotation, and greater loss of medial rotation.

The values of the statistical analysis of the variable pain, with the variables mobility LR and MR90, strength LR90 and MR90, ROM, GLR and GIRD are shown in Table 5.

In all the athletes evaluated, the relationship between GIRD/GLR was calculated to identify the athletes with "shoulder at risk" (GIRD/GLR > 1). Forty athletes $(73 \%)$ were found in this condition, which were compared with the other $15(27 \%)$, both with varying degrees of pain. The result showed a statistically significant association between pain and "shoulder at risk" ( $p=0.028)$.

Table 5 - Results of the statistical analysis by Fisher's exact test.

\begin{tabular}{c|c}
\hline Pain x Mob LR90 & $\mathrm{p}=0.707$ \\
\hline Pain x Mob MR90 & $\mathrm{p}=0.053$ \\
\hline Pain x Strength LR90 & $\mathrm{p}=0.322$ \\
\hline Pain x Strength MR90 & $\mathrm{p}=0.602$ \\
\hline Pain x ROM & $\mathrm{p}=0.015$ \\
\hline Pain x GLR & $\mathrm{p}=0.831$ \\
\hline Pain x GIRD & $\mathrm{p}=0.210$
\end{tabular}

Legend - LR90: lateral rotation at 90 degrees of abduction, MR90: medial rotation at 90 degrees of abduction, Mob: mobility, ROM: range of motion, GLR: gain in lateral rotation, GIRD: glenohumeral internal rotation deficit.

Source: Outpatient clinic of the Shoulder and Elbow Group of the DOT-ISCMSP

\section{DISCUSSION}

The pitchers developed marked alterations in mobility of the dominant shoulder, with excessive lateral rotation and limited medial rotation at 90 degrees of abduction $^{(7,14-16)}$. Our data corroborates the literature, which also describes this adaptation. We found, with the shoulder at 90 degrees of abduction, an average value for lateral rotation of $110^{\circ}$ in the dominant limb, compared with $105^{\circ}$ in the contralateral limb, with a statistically significant difference $(p=0.003)$. The average value, in our study, for medial rotation at 90 degrees of abduction was $61^{\circ}$ in the dominant limb and $75^{\circ}$ in the contralateral $\operatorname{limb}$, with a statistically significant difference $(p<0.001)$, which is similar to the results of other authors ${ }^{(8,15,17)}$.

The differences in patterns of mobility in the shoulder are also apparent in the results on GLR and GIRD. According to Borsa et $\mathrm{al}^{(18)}$, the value of GLR ranges from $5^{\circ}$ to $10^{\circ}$ while GIRD occurs from $8^{\circ}$ to $15^{\circ}$. According to Brown et $\mathrm{al}^{(19)}$, the GIRD in pitchers without a history of shoulder injuries ranges from $10^{\circ}$ to $15^{\circ}$. The athletes of our study presented an average GIRD value that is slightly above the averages found in the literature, and this may be associated at the start of development of injuries. In a study on the 
alterations in mobility in baseball players, Myers et $\mathrm{al}^{(20)}$ found an average GIRD of $11.1^{\circ}$ in athletes without a history of injury; however, the authors showed that the group consisting of athletes with a diagnosis of posterior internal impact had an average value for GIRD of $19.7^{\circ(20)}$. According to Borsa et $\mathrm{al}^{(18)}$, pitchers with GIRD greater than or equal to $19^{\circ}$ present pathological structural alterations in the shoulder. Burkhart et $\mathrm{al}^{(10)}$ observed posterior capsule contracture in all 24 pitchers submitted to surgical treatment of type II SLAP lesion, and that all these patients had GIRD in the dominant shoulder that was $25^{\circ}$ higher than in the non-dominant shoulder.

The values of GLR and GIRD were evaluated with the data on player's position, observing that the pitchers had higher average values for GLR and GIRD than the non-pitchers, with a statistically significant difference between the groups, a finding that is in accordance with the studies of Wilk et $\mathrm{al}^{(15)}$, Brown et $\mathrm{al}^{(19)}$ and Bigliani et $\mathrm{al}^{(21)}$.

Also in relation to the pattern of mobility of the shoulder, the concept of "range of motion" described by Wilk et al ${ }^{(15)}$ suggests that the values for ROM in the pitcher's dominant limb would be equal (with a variation of $5^{\circ}$ ) to those of the non-dominant limb, but there are differences between them in terms of their composition; the ROM of the dominant limb has greater lateral rotation and less medial rotation ${ }^{(18)}$. Crockett et $\mathrm{al}^{(16)}$ found a similar result in their pitchers with an average value for ROM of $189^{\circ}$ for both shoulders. Our results for ROM show separate average values for the dominant limb $\left(171^{\circ}\right)$ and the contralateral limb $\left(181^{\circ}\right)$, with a statistically significant difference between the groups $(\mathrm{p}<0.001)$.

Besides the pattern of mobility, the profiles for muscle strength were also evaluated in our athletes' shoulders. There is no consensus in the literature regarding the alterations described about the patterns of muscle strength in pitchers ${ }^{(12,15,22)}$. We found similar average values for medial rotation strength in the dominant and non-dominant limbs (11.97kgf and 12.25kgf, respectively), though not statistically significant, and similar average values for lateral rotation strength in the dominant and non-dominant limbs $(13.67 \mathrm{kgf}$ and $13.52 \mathrm{kgf}$, respectively) also not statistically significant. Our results were similar to those of Brown et $\mathrm{al}^{(19)}$.

It is believed that many injuries caused by the pitching motion in professional players are the result of repetition microtraumas that occur in the early stages of practicing the sport ${ }^{(23)}$. Although muscle fatigue is considered normal and even necessary in the training of an athlete, joint pain is not. According to Wilk et $\mathrm{al}^{(15)}$, pain in the pitcher's shoulder is a warning sign of the development of overload injuries. We believe that shoulder pain in pitchers is a sign of possible overload injury, and that its origin and occurrence are related to factors such as length of time spent playing the sport, weekly amount of training and playing position. According to Lyman et $\mathrm{al}^{(24)}$, the complaint of pain on pitching was present in $32 \%$ of the teen pitchers evaluated. The same author published another study, after one year, with a different population of athletes, and observed that $35 \%$ of the athletes complained of pain $^{(23)}$. Trakis et $\mathrm{al}^{(17)}$, in an evaluation of adolescent baseball players, all pitchers, observed complaints of pain on pitching in 12 out of 23 athletes. In our study, $36 \%$ of the athletes evaluated had a history of pain. Also in this regard, we evaluated the influence of the playing position and its relationship with the variable pain, and found that, for our population, there was no statistically significant correlation between these variables. The number of training sessions per week (from two to four sessions) did not show a statistical correlation with the variable pain; however, the length of time spent playing the sport showed a positive statistical correlation with the variable pain. The athletes who reported pain had played the sport for longer than the asymptomatic athletes. Given that pain is a sign of possible lesions by repetition microtraumas ${ }^{(23,25)}$, the hypothesis that the length of time spent playing the sport is related to the history of pain is plausible.

The statistical correlation between the variable pain and the values for lateral and medial rotation with the shoulder abducted at $90^{\circ}$ did not show a statistical significance; however, the $p$ value found $(p=0.053)$ suggests a statistical tendency towards an association between these variables, which would be a warning sign for the development of "shoulder at risk".

The evaluation of the association between the variable pain and the distribution of the values for strength did not show any statistical significance. According to Wilk et $\mathrm{l}^{(25)}$, the balance between the agonist and antagonist musculature of the pitcher's shoulder is necessary for dynamic stabilization, and this is achieved when the values for strength of the lateral rotators are at least $65 \%$ of the values for strength of the medial 
rotators. Our results are in accordance with those of the authors, as the average values of strength for lateral rotation with $90^{\circ}$ of abduction are greater than those for medial rotation.

The correlation of the data for ROM with the variable pain was statistically significant $(p=0.0015)$, suggesting that the athletes with lower ROM are the ones that present more complaints of pain, this being a possible cause of the difference between the average values for ROM in the pitchers' shoulders. According to Burkhart et $\mathrm{al}^{(10)}$, shoulder injuries in pitchers can occur if the values for ROM are less than $180^{\circ}$ and if the GIRD is greater than $25^{\circ}$. According to Burkhart et $\mathrm{al}^{(11)}$, when the GIRD exceeds the GLR (GIRD/GLR ratio $>1$ ), the shoulder may be at risk of injuries due to the change in glenohumeral kinematics in the late cocking phase of pitching. These authors also affirm that the higher the value of this ratio, the greater the risk of development of injuries. "Shoulder at risk" was found in $40(73.2 \%)$ of the 55 athletes evaluated, and we also observed a statistically significant correlation between those with "shoulder at risk" and the variable pain $(p=0.028)$. According to Bach and Goldberg ${ }^{(4)}$, research on clinical signs of contracture of the posterior inferior capsule is recommended at the start and at the

\section{REFERENCES}

1. Ejnisman B, Andreoli CV, Carrera EF, Abdalla RJ, Cohen M. Lesões musculoesqueléticas no ombro do atleta: mecanismo de lesão, diagnóstico e retorno à prática esportiva. Rev Bras Ortop. 2001;36(10):389-93.

2. Cavallo RJ, Speer KP. Shoulder instability and impingement in throwing athletes. Med Sci Sports Exerc.1998;30(Suppl 4):S18-25.

3. Murachovsky J, Ikemoto RY, Nascimento LGP, Bueno RS, Coelho JA, Komeçu MT, et al. Avaliação da retroversão do úmero em jogadores de handebol. Acta Ortop Bras. 2007;15(5):258-61.

4. Bach HG, Goldberg BA. Posterior capsular contracture of the shoulder. J Am Acad Orthop Surg. 2006;14(5):265-77.

5. Morgan CD. Recognition and effective treatment of GIRD, internal impingement and symptomatic SLAP lesions in overhead throwing athletes. In: Symposium presented in AANA Specialty Day, AAOS San Francisco, California, 2008.

6. Papas AM, Zawacki RM, McCarthy CF. Rehabilitation of the pitching shoulder. Am J Sports Med. 1985;13(4):223-35.

7. Braun S, Kokmeyer D, Millet P. Current concepts review - Shoulder injuries in the throwing athlete. J Bone Joint Surg Am. 2009;91:966-78.

8. Downar JM, Sauers EL. Clinical measures of the shoulder mobility in the professional baseball player. J Athl Train. 2005;40(1):23-9.

9. Grossman MG, Tibone JE, McGarry MH, Schneider DJ, Veneziani S, Lee TQ. A cadaveric model of the throwing shoulder: a possible etiology of superior labrum anterior-to-posterior lesions. J Bone Joint Surg Am. 2005;87(4):824-31.

10. Burkhart SS, Morgan CD, Kibler BW. The disable throwing shoulder: spectrum of pathology part I: pathoanatomy and biomechanics. Arthroscopy. 2003;19(6):404-20.

11. Burkhart SS, Morgan CD, Kibler BW. The disable throwing shoulder: spectrum of pathology part III: the sick scapula, scapular dyskinesis, the kinetic chain and rehabilitation. Arthroscopy. 2003;19(6):641-61.

12. Magnusson SP, Glein GW, Nicholas JA. Shoulder weakness in professional baseball pitchers. Med Sci Sports Exerc. 1994;26(1):5-9.

13. Hawkins RJ, Bokos DJ. Clinical evaluation of shoulder problems. I: Rockwood CA Jr, Matsen FA 3rd. The shoulder. 2nd ed. Philadelphia:Saunders; 1998. p.175-80. end of the baseball season, due to its association with pitching injuries. We suggest that the evaluation of "shoulder at risk" is useful for identifying athletes with potential lesions that could be detrimental to their performance.

\section{CONCLUSION}

Statistically significant differences were found for mobility of the shoulder at 90 degrees of abduction in the dominant limb of the baseball players evaluated, with an increase in lateral rotation $(p=0.003)$, decrease in medial rotation $(p<0.001)$ and less range of movement $(p<0.001)$ in relation to the contralateral limb.

Statistically significant relationships were found between greater GLR $(p=0.013)$ and GIRD $(p=0.033)$ and the pitcher's playing position.

There was a statistically significant correlation between the variable pain and decreased range of motion $(p=0.015)$, longer time playing the sport $(p=0.016)$ and situation of "shoulder at risk" $(\mathrm{p}=0.028)$.

There is a statistical trend that suggests that decreased medial rotation of the dominant shoulder was related to the variable pain in the athletes $(p=0.053)$.

14. Donatelli R, Ellenbecker TS, Ekedahl SR, Wilkes JS, Kocher K, Adam J. Assessment of shoulder strength in professional baseball pitchers. J Orthop Sports Phys. 2000;30(9):544-51.

15. Wilk KE, Meister K, Andrews JR. Current concepts in the rehabilitation of the overhead throwing athlete. Am J Sports Med. 2002;30(1):136-51.

16. Crockett HC, Gross LB, Wilk KE, Schwartz ML, Reed J, O’Mara J, et al. Osseus adaptation and range of motion at the glenohumeral joint in professional baseball pitchers. Am J Sports Med. 2002;30(1):20-6.

17. Trakis JE, McHugh MP, Caracciolo PA, Busciacco L, Mullaney M, Nicholas SJ. Muscle strength and range of motion in adolescent pitchers with throwing-related pain. Am J Sports Med. 2008;36(11):2173-8.

18. Borsa PA, Laudner KG, Sauers EL. Mobility an stability adaptations in the shoulder of the overhead athlete: a theoretical and evidence-based perspective. Sports Med. 2008;38(1):17-36.

19. Brown LP, Niechues SL, Harrah A, Yavorsky P, Hirshman HP. Upper extremity range of motion and isokinetic strength of the internal and external shoulder rotators in major league baseball players. Am J Sports Med. 1988; 16(6):577-85.

20. Myers JB, Laudner KG, Pasquale MR, Bradley JP, Lephart SM. Glenohumeral range of motion deficits and posterior shoulder tightness in throwers with pathologic internal impingement. Am J Sports Med. 2006;34(3):385-91.

21. Bigliani LU, Codd TP, Connor PM, Levine WN, Littlefield MA, Hershon SJ. Shoulder motion and laxity in the professional baseball player. Am J Sports Med. 1997;25(5):609-13.

22. Noffal GJ. Isokinetic eccentric-to-concentric strength ratios of the shoulder rotator muscles in throews and nonthrowers. Am J Sports Med. 2003;31(4):537-41.

23. Lyman S, Fleisig GS, Andrews JR, Osinski ED. Effect of pitch type, pitch count and pitching mechanics on risk of elbow and shoulder pain in youth baseball pitchers. Am J Sports Med. 2002;30(4):463-8.

24. Lyman S, Fleisig GS, Waterbor JW, Funkhouser EM, Pulley L, Andrews JR, et al. Longitudinal study of elbow and shoulder pain in youth baseball pitchers. Med Sci Sports Exerc 2001;33(11):1803-10.

25. Wilk KE, Obma P, Simpson CD, Cain EL, Dugas J, Andrews JR. Shoulder injuries in the overhead athlete. J Orthop Sports Phys Ther. 2009;39(2):38-54. 